\title{
Severe hypovitaminosis $D$ in chronic kidney disease: association with blood pressure and coronary artery calcification
}

\author{
Roberta Pillar, Miriam Ghedini G Lopes, Lillian Andrade Rocha, Lilian Cuppari, Aluízio B Carvalho, \\ Sérgio A Draibe and Maria Eugênia F Canziani
}

Hypovitaminosis D occurs early in the course of chronic kidney disease (CKD), and its association with cardiovascular morbidity and mortality is well known. In this study, we aimed to evaluate whether the degree of hypovitaminosis $\mathrm{D}$ may differently affect blood pressure (BP) and coronary artery calcification (CAC) in nondialyzed CKD patients. This study included 80 CKD patients with a creatinine clearance between 15 and $60 \mathrm{ml} / \mathrm{min} / 1.73 \mathrm{~m}^{2}$ and serum 25 hydroxivitamin $D$ [25(OH)D] level $<30 \mathrm{ng} / \mathrm{ml}$. Patients underwent 24-h ambulatory BP monitoring, evaluation of CAC (multi-slice computed tomography), and laboratory evaluation. Two groups, based on the degree of hypovitaminosis D, were defined according to the median 25(OH)D value. Patients with severe hypovitaminosis D $[25(\mathrm{OH}) \mathrm{D}<17.2 \mathrm{ng} / \mathrm{ml}$; S-group) exhibited a higher systolic BP at all time periods (24-h, nighttime, daytime) when compared to patients with mild hypovitaminosis D [25(OH)D $>17.2 \mathrm{ng} / \mathrm{ml}$; M-group]. No differences were found between the $\mathrm{S}$ and $\mathrm{M}$-group in terms of diastolic BP and the presence of coronary calcification. In the multiple linear regression analysis, severe hypovitaminosis D was a predictor of 24-h, daytime and nighttime BP after controlling for a number of confounders. The severity of hypovitaminosis D was associated with increased BP in nondialyzed CKD patients. The degree of hypovitaminosis $\mathrm{D}$ was not related to $\mathrm{CAC}$, which was equally elevated in both the severe and mild hypovitaminosis $\mathrm{D}$ groups. Hypertension Research (2013) 36, 428-432; doi:10.1038/hr.2012.230; published online 31 January 2013

Keywords: blood pressure; hypovitaminosis D; nondialysis patients; vascular calcification

\section{INTRODUCTION}

Vitamin D is an essential micronutrient with important implications for human heath. ${ }^{1}$ There is evidence that beyond its actions on mineral metabolism, vitamin D may also have pleiotropic effects on the cardiovascular system. ${ }^{2}$ Worldwide, approximately 1 billion people have hypovitaminosis $\mathrm{D},{ }^{3}$ which is characterized by a serum 25-hydroxivitamin D $(25(\mathrm{OH}) \mathrm{D})$ level $<30 \mathrm{ng} \mathrm{ml}^{-1}$. Notably, a large number of studies have demonstrated an association between lower vitamin $\mathrm{D}$ levels and an increased risk of fatal and nonfatal cardiovascular events in the general population. ${ }^{4-6}$

Cardiovascular disease is the leading cause of death in patients with chronic kidney disease (CKD). In the last few years, the association of low 25(OH)D levels with higher cardiovascular mortality was confirmed in dialysis as well as in nondialysis CKD patients. ${ }^{7-9}$

These findings are in agreement with the increasing body of evidence that supports the important role of vitamin $\mathrm{D}$ in the pathogenesis of cardiovascular diseases. ${ }^{10}$ Matias et al. ${ }^{11}$ found that $25(\mathrm{OH}) \mathrm{D}$ was strongly associated with brain natriuretic peptide, pulse pressure and the presence of vascular calcification in hemodialysis patients. The inverse and independent association between serum $25(\mathrm{OH}) \mathrm{D}$ levels and the development of coronary calcification in patients with kidney dysfunction has been corroborated by some authors, ${ }^{12,13}$ but not by others. ${ }^{14}$ Finally, although not consistent across all studies, a number of reports of the general population support the hypothesis that suboptimal vitamin D status is associated with an increased risk of hypertension. ${ }^{15,16}$ A loss of regulation of the renin-angiotensin-aldosterone system, inflammation and proliferation and hypertrophy of the myocardial cells are among the potential mechanisms involved. ${ }^{17}$ The putative relationship between hypovitaminosis $\mathrm{D}$ and hypertension in $\mathrm{CKD}$, however, has been rarely investigated. ${ }^{18}$

Hypovitaminosis D occurs early in the course of CKD, and its association with cardiovascular morbidity and mortality has been recognized. In this study, we aimed to evaluate whether the degree of hypovitaminosis D affects blood pressure (BP) and coronary artery calcification (CAC) in nondialyzed CKD patients.

\section{METHODS}

Patients

Eighty patients with a creatinine clearance between 15 and $60 \mathrm{ml} \mathrm{min}^{-1}$ per $1.73 \mathrm{~m}^{2}$ and serum $25(\mathrm{OH}) \mathrm{D}<30 \mathrm{ng} \mathrm{ml}^{-1}$ were recruited from the outpatient clinic of the Federal University of São Paulo, Brazil. Exclusion criteria included 
age $<18$ years and $>85$ years, nephrotic syndrome, immobilization in the last 3 months, liver disease, autoimmune disease, infection, neoplasia and positive serology for HIV. Additional exclusion criteria included supplementation with vitamin $\mathrm{D}$ or analogs, the use of corticosteroids and immunosuppressive drugs in the last three months, and hypercalcemia (ionized calcium $>1.40 \mathrm{mmoll}^{-1}$ ) and/or a serum parathormone (PTH) level $>500 \mathrm{pg} \mathrm{ml}^{-1}$. Seventy-nine patients (99\%) were on regular antihypertensive therapy, 27 (34\%) were using three different classes of drugs and $20(25 \%)$ were using more than three different classes of drugs. Angiotensin-converting enzyme inhibitors were used by 52 patients $(65 \%)$.

Written informed consent was obtained from all participants, and the study was approved by the University Ethical Advisory Committee. This study is part of an ongoing protocol on cholecalciferol supplementation and is in accordance with the ethical principles of the Declaration of Helsinki. The study is registered at The Brazilian Clinical Trials Registry (REBEC-Registro Brasileiro de Ensaios Clínicos, RBR-6pngwz), which belongs to the International Clinical Trial Registry Platform of the World Health Organization (ICTRP/WHO: U1111-1126-2741)

\section{Laboratory measurements}

Blood samples were drawn in a 12-hour fasting state for the evaluation of serum creatinine, hemoglobin, albumin (bromocresol green), bicarbonate, ionized calcium, phosphorus, alkaline phosphatase, intact PTH (reference values: $10-65 \mathrm{pg} \mathrm{ml}^{-1}$; chemiluminescence, DPC, Medlab, San Antonio, TX, USA), 25(OH)D (reference values: 18-62 ng/dl; radioimmunoassay, DiaSorin, MN, USA), intact fibroblast growth factor-23 (FGF-23, ELISA Kainos Laboratories, Tokyo, Japan; reference range $27.8-30 \mathrm{pg} \mathrm{ml}^{-1}$ ), lipid profile, high-sensitivity C-reactive protein (reference value: $<0.11 \mathrm{mg} \mathrm{dl}^{-1}$; immunonephelometry) and renin (HPLC, high-performance liquid chromatography). Angiotensin-converting enzyme activity was determined fluorometrically using Z-Phe-His-Leu as a substrate. Urinary protein and phosphorus were measured by 24 -h urine collection. The glomerular filtration rate was estimated using the Modification of Diet in Renal Disease (MDRD) Study equation. Hyperphosphatemia and hyperparathyroidism were considered when serum phosphorus and $\mathrm{iPTH}$ levels were higher than the upper limit of the normal range ( $>4.6 \mathrm{mg} \mathrm{dl}^{-1}$ and $>65 \mathrm{pg} \mathrm{ml}^{-1}$, respectively), as proposed by the Kidney Disease Improving Global Outcomes (KDIGO) Guideline on Mineral and Bone Disorder of Chronic Kidney Disease. ${ }^{19}$ Dyslipidemia was defined according to the NCEP III guidelines (National Cholesterol Education Program-Adult Treatment Panel (ATP) III). ${ }^{20}$

\section{Blood pressure recording}

Twenty-four hour ambulatory $\mathrm{BP}$ monitoring (ABPM) was performed using Dyna-MAP (Cardios, São Paulo, Brazil) equipment, which was approved by the Association for the Advancement of Medical Instrumentation. Blood pressure measurements were obtained at 20-minute intervals during the day and 30-minute intervals during the night. The participants were instructed to keep their habitual routine during the 24-h period and to pause momentarily during each BP measurement. Dipping (\%) was defined as the percent decrease in nighttime systolic-diastolic BP compared with daytime systolicdiastolic BP. When patients exhibited dipping of $<10 \%$, they were defined as non-dippers. Hypertension was defined as a BP $>140 / 90 \mathrm{~mm} \mathrm{Hg}$ or the use of antihypertensive medication.

\section{Coronary artery calcification}

Patients underwent coronary artery calcification (CAC) quantification with a multislice computed tomography scanner (LightSpeed Pro 16-GE Healthcare, Milwaukee, WI, USA), using a gantry rotation of $0.4 \mathrm{~s}$, collimation of $2.5 \mathrm{~mm}$ (slice thickness) and reconstruction time of 6 frames per second. A calcium threshold of $\geqslant 130 \mathrm{HU}$ (Hounsfield units) was used. The images were scored by a single radiologist who was blinded to the clinical and biochemical information of the patients. As described by Agatston, the calcium score was determined by multiplying the area of each calcified lesion by a weighting factor corresponding to the peak pixel intensity for each lesion. ${ }^{21}$ The sum of each lesion of all the coronary arteries was used for the analysis. The presence of calcification was defined as a CAC score $>10 \mathrm{AU}$ (Agatston units), and severe calcification was defined as a CAC score of $\geqslant 400 \mathrm{AU}$.

\section{Statistical analysis}

Data are reported as the mean and s.d., median (interquartile range) or frequency. Groups of hypovitaminosis D were defined according to the median $25(\mathrm{OH}) \mathrm{D}$ value. Thus, a $25(\mathrm{OH}) \mathrm{D}$ level $>17.2 \mathrm{ng} \mathrm{ml}^{-1}$ was defined as the mild hypovitaminosis D group (M-group) and a $25(\mathrm{OH}) \mathrm{D}$ level $<17.2 \mathrm{ng} \mathrm{ml}^{-1}$ was defined as the severe hypovitaminosis D group (S-group). Comparisons of continuous variables were performed using a Student's independent $t$-test and Mann-Whitney $U$-test for normal and skewed data, respectively. Comparisons of proportions were performed using $\chi^{2}$ analysis or a Fischer's exact test, as appropriate. Multiple linear regression analyses (stepwise) were performed to evaluate the association of the degree of hypovitaminosis $\mathrm{D}$ with $\mathrm{BP}$. A $P$-value $<0.05$ was considered to be statistically significant. All statistical analyses were performed using SPSS (Statistical Package for the Social Sciences) for Windows version 16.0 (SPSS Inc., Chicago, IL, USA).

\section{RESULTS}

Table 1 depicts the characteristics of the study participants. The population is mostly composed of elderly patients with a high prevalence of cardiovascular risk factors. Hypertension was found in the majority of the patients (99\%), and diabetes was found in almost $60 \%$ of the patients. Overweight (BMI $25-29.9 \mathrm{~kg} \mathrm{~m}^{-2}$ ) and obesity $\left(\mathrm{BMI} \geqslant 30 \mathrm{~kg} \mathrm{~m}^{-2}\right.$ ) were found in $33 \%$ and $27 \%$ of the cohort, respectively. Forty-seven patients (59\%) were classified as CKD stage 3 , and $33(41 \%)$ were classified as stage 4 . Proteinuria was found in $34 \%$, and a CRP $>0.11 \mathrm{mg} \mathrm{dl}^{-1}$ was found in $85 \%$ of the patients. At least one lipid profile abnormality was observed in $82 \%$ of the patients. Hyperphosphatemia and hyperparathyroidism were observed in 6 and $75 \%$ of the patients, respectively.

Although the mean values of both systolic and diastolic pressures were within the normal range, $36 \%$ of the patients had high BP. A non-dipper pattern was found in $46 \%$ of the patients. The presence of CAC (calcium score $>10 \mathrm{AU}$ ) was observed in 57 patients $(71 \%)$, and $24(30 \%)$ of these patients had severe CAC (calcium score $\geqslant 400 \mathrm{AU})$. Compared with the patients without calcification, those with CAC were older ( $70 \pm 9$ years versus $54 \pm 15$ years; $P<0.01$ ), and no clinical or laboratorial differences were found between the groups.

Comparisons of the patients according to the degree of hypovitaminosis D are shown in Table 1. The S-group had a higher prevalence of diabetes, proteinuria, serum glucose, iPTH and alkaline phosphatase, and a lower ionized calcium concentration. Additionally, there was a trend towards a higher phosphorus level in this group. As can be seen in Figure 1, the S-group exhibited a higher systolic BP at all time periods (24-hour, nighttime, daytime). No differences were found between the S- and M-group in terms of the diastolic BP and non-dipper pattern. The type and number of antihypertensive drugs in both groups were similar. The prevalence of coronary calcification was $70 \%$ in the S-group and $72.5 \%$ in the $\mathrm{M}$-group $(P=0.80)$. The calcium score and other clinical and laboratory parameters did not differ between the $\mathrm{S}$ and $\mathrm{M}$-group.

In the multiple linear regression analysis, severe hypovitaminosis D was a predictor of 24-h BP, daytime BP and nighttime BP after including a number of confounders, such as age, diabetes, renal function, phosphorus, calcium, iPTH and renin. The final regression models are depicted in Table 2.

\section{DISCUSSION}

This study demonstrated the independent association of the severity of hypovitaminosis D with increased BP in nondialyzed CKD patients. Considering the burden of cardiovascular risk factors 
Table 1 Characteristics of the patients according to the degree of hypovitaminosis D

\begin{tabular}{|c|c|c|c|c|}
\hline & $A / l(\mathrm{n}=80)$ & S-group $25(\mathrm{OH}) D<17.2(\mathrm{n}=40)$ & M-group $25(\mathrm{OH}) D>17.2(\mathrm{n}=40)$ & P-value \\
\hline Age (years) & $65 \pm 13$ & $64 \pm 14$ & $66 \pm 12$ & 0.34 \\
\hline Gender (females), $n(\%)$ & $40(50)$ & $21(52)$ & $19(47)$ & 0.65 \\
\hline Dark skin color, $n(\%)$ & $35(48)$ & $18(45)$ & $17(42)$ & 0.82 \\
\hline \multicolumn{5}{|l|}{ CKD etiology } \\
\hline Diabetic nephropathy, $n(\%)$ & $21(26)$ & $14(35)$ & $7(17)$ & \multirow[t]{4}{*}{0.14} \\
\hline Hypertensive nephropathy, $n(\%)$ & $20(25)$ & $6(15)$ & $14(35)$ & \\
\hline Unknown, $n(\%)$ & $17(21)$ & 7 (17) & $10(25)$ & \\
\hline Other, $n(\%)$ & $22(28)$ & $13(33)$ & $9(23)$ & \\
\hline Hypertension, $n(\%)$ & $78(97.5)$ & $39(97.5)$ & $39(97.5)$ & 1.00 \\
\hline Diabetic, $n(\%)$ & $39(58)$ & $25(62)$ & $14(35)$ & 0.02 \\
\hline Dyslipidemia, $n(\%)$ & $49(61)$ & $35(87)$ & $31(77)$ & 0.23 \\
\hline Sedentarism, $n(\%)$ & $49(61)$ & $25(62.5)$ & $24(60)$ & 0.81 \\
\hline \multirow{2}{*}{\multicolumn{5}{|c|}{ Laboratory parameters }} \\
\hline & & & & \\
\hline eGFR (ml min per $\left.1.73 \mathrm{~m}^{2}\right)$ & $28 \pm 9$ & $28 \pm 11$ & $29 \pm 8$ & 0.93 \\
\hline Proteinuria (mg per $24 \mathrm{~h}$ ) & $0.20(0-0.63)$ & $0.4(0-1.23)$ & $0(0-0.4)$ & 0.01 \\
\hline Hemoglobin $\left(\mathrm{g} \mathrm{dl}^{-1}\right)$ & $13.2 \pm 1.86$ & $13.1 \pm 1.87$ & $13.3 \pm 1.87$ & 0.58 \\
\hline Blood glucose $\left(\mathrm{mg} \mathrm{dl}^{-1}\right)$ & $91(83-111)$ & $100(85-151)$ & $90(80-98)$ & 0.02 \\
\hline $\mathrm{HDL}\left(\mathrm{mg} \mathrm{dl}^{-1}\right)$ & $44 \pm 10.55$ & $45 \pm 11$ & $44 \pm 10$ & 0.59 \\
\hline $\operatorname{LDL}\left(\mathrm{mg} \mathrm{dl}^{-1}\right)$ & $97(76-122)$ & $97(74-122)$ & $97(7 \overline{7}-121)$ & 0.88 \\
\hline Triglycerides (mg dl ${ }^{-1}$ ) & $143(103-197)$ & $159(96-235)$ & $141(112-174)$ & 0.62 \\
\hline $\mathrm{CRP}\left(\mathrm{mgl}^{-1}\right)$ & $0.36(0.15-0.91)$ & $0.26(0.14-0.89)$ & $0.41(0.16-0.98)$ & 0.45 \\
\hline lonized calcium (mmoll-1) & $1.30 \pm 0.04$ & $1.29 \pm 0.05$ & $1.31 \pm 0.03$ & 0.01 \\
\hline Phosphorus (mg dl ${ }^{-1}$ ) & $3.5 \pm 0.63$ & $3.6 \pm 0.67$ & $3.3 \pm 0.57$ & 0.06 \\
\hline Alkaline phosphatase $\left(\mathrm{UI}^{-1}\right)$ & $86 \pm 29.4$ & $95 \pm 33$ & $76 \pm 21$ & 0.003 \\
\hline iPTH (pg ml-1) & $100(70-154)$ & $109(83-162)$ & $88(56-142)$ & 0.05 \\
\hline $25(\mathrm{OH}) \mathrm{D}(\mathrm{ng} \mathrm{dl}-1)$ & $17.20 \pm 5.85$ & $12 \pm 2.89$ & $22 \pm 3.59$ & $N A$ \\
\hline Phosphaturia (mg per $24 \mathrm{~h}$ ) & $419(323-517)$ & $426(341-517)$ & $405(316-519)$ & 0.51 \\
\hline FGF23 $\left(\mathrm{pg} \mathrm{ml}^{-1}\right)$ & $66.3(43-101)$ & $64(40-117)$ & $68(45-102)$ & 0.96 \\
\hline ACE $(\mathrm{nmo} \mathrm{ml} \mathrm{min}-1)$ & $106.5 \pm 44.7$ & $111.2 \pm 50.9$ & $101.8 \pm 37.5$ & 0.35 \\
\hline Renin $\left(\mathrm{nmol} \mathrm{ml} \mathrm{h}{ }^{-1}\right)$ & $0.22 \pm 0.11$ & $0.22 \pm 0.10$ & $0.21 \pm 0.12$ & 0.58 \\
\hline \multicolumn{5}{|l|}{ Blood pressure $(\mathrm{mm} \mathrm{Hg})$} \\
\hline 24-h systolic & $127 \pm 17$ & $131 \pm 17$ & $123 \pm 15$ & 0.02 \\
\hline 24-h diastolic & $72 \pm 10$ & $72 \pm 10$ & $71 \pm 11$ & 0.68 \\
\hline Nighttime systolic & $114(105-129)$ & $123(109-135)$ & $112(99-122)$ & 0.01 \\
\hline Nighttime diastolic & $66 \pm 12$ & $66 \pm 11$ & $65 \pm 12$ & 0.51 \\
\hline Daytime systolic & $126 \pm 22$ & $131 \pm 23$ & $121 \pm 20$ & 0.04 \\
\hline Daytime diastolic & $72 \pm 14$ & $73 \pm 12$ & $72 \pm 16$ & 0.73 \\
\hline Non-dipper, $n(\%)$ & $36(46)$ & $18(50)$ & $18(50)$ & 0.91 \\
\hline Calcium Score (AU) & $98(1-458)$ & $84(1-498)$ & $106(0-427)$ & 0.88 \\
\hline $\mathrm{CAC}(\geqslant 10 \mathrm{AU}), n(\%)$ & $57(71 \%)$ & $28(70 \%)$ & $29(72.5 \%)$ & 0.80 \\
\hline
\end{tabular}

Abbreviations: ACE, Angiotensin converting enzyme; BMI, body mass index; CAC, coronary artery calcification; CKD, chronic kidney disease; CRP, C-reactive protein; eGFR, estimated glomerular filtration rate; FGF23, fibroblast growth factor 23; iPTH, parathyroid hormone.
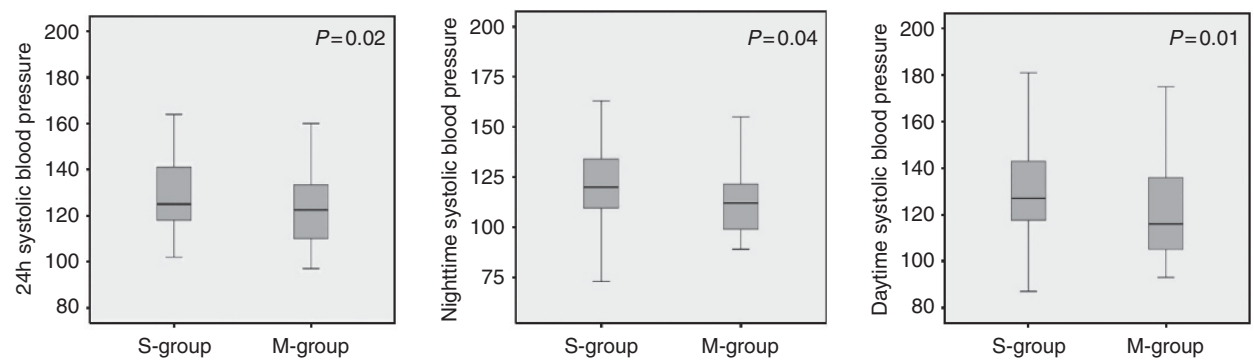

Figure 1 Systolic blood pressure in patients with severe hypovitaminosis D and with mild hypovitaminosis D.

associated with poor vitamin D status that has been evidenced in the past years, understanding the cardiovascular consequences promoted by severe hypovitaminosis $\mathrm{D}$ in the early stages of CKD is important.

Hypovitaminosis D is very common within the general population and is highly prevalent among CKD patients, even in earlier stages of the disease. Previous studies have demonstrated that the prevalence of hypovitaminosis D varies from 40 to $86 \%$ among nondialyzed patients $^{22-24}$ and from 77 to $100 \%$ among patients on dialysis. ${ }^{24-26}$ A recent study from NECOSAD observed that $87 \%$ of dialysis patients had hypovitaminosis $\mathrm{D}$, and $\sim 30 \%$ of these patients had severe hypovitaminosis $\mathrm{D}$, which was defined in the study as a $25(\mathrm{OH}) \mathrm{D}$ level $<10 \mathrm{ng} \mathrm{ml}^{-1}$. 7 Similar proportions of severe hypovitaminosis D have been found among patients in the nondialysis stages. ${ }^{27}$ Some groups are more susceptible to vitamin D deficiency, including the elderly, diabetics and obese patients. ${ }^{28}$ Elderly patients usually have reduced exposure to sunlight, reduced mobility and lower cutaneous synthesis of vitamin D. Diabetics have a higher degree of proteinuria with subsequent loss of the vitamin D carrier. In addition, autonomic 
Table 2 Multiple linear regression analysis with systolic blood pressure as a dependent variable

\begin{tabular}{lrcr}
\hline & $\beta$ & $95 \% ~ C l$ & P-value \\
\hline Panel A: 24-h SBP & & & \\
S-group & -9.53 & $-16.93--2.13$ & 0.012 \\
Age & 0.35 & $0.07-0.62$ & 0.013 \\
Constant & 109.44 & $91.23-127.64$ & $<0.001$ \\
& & & \\
Panel B: Daytime SBP & & & 0.011 \\
S-group & -16.35 & $-28.88--3.82$ & $<0.001$ \\
Constant & 135.53 & $117.74-153.31$ & \\
& & & 0.028 \\
Panel C: Nighttime SBP & & & 0.008 \\
S-group & -9.98 & $-18.89--1.08$ & $<0.001$ \\
Age & 0.44 & $0.11-0.77$ & \\
Constant & 92.60 & $70.67-114.52$ & \\
\hline
\end{tabular}

Abbreviations: $\mathrm{Cl}$, confidence interval; SBP, systolic blood pressure.

neuropathy, which may lead to a deficit in absorption, contributes to a deficiency of vitamin D. ${ }^{29}$

One of the most accepted theories that associates obesity with hypovitaminosis $\mathrm{D}$ is that vitamin $\mathrm{D}$ is a fat-soluble substance that can easily be sequestered and stored in the adipose tissue. ${ }^{30}$ Accordingly, a recent study indicated that obesity and diabetes are the most important risk factors for hypovitaminosis $\mathrm{D}$ in nondialyzed CKD patients. ${ }^{31}$ In the present study, although age and the prevalence of overweight patients did not differ between the S- and M-group, the frequency of diabetes was substantially higher in the former group.

Increasing evidence exists supporting the premise that low $25(\mathrm{OH}) \mathrm{D}$ levels result in the development of cardiovascular complications in the general population as well as in CKD patients. ${ }^{10}$ Our study is in agreement with the available studies in non-CKD subjects and shows the association between low vitamin D levels and high BP. $^{32}$ The Third National Health and Nutrition Examination Survey (NHANES III) included >12000 participants, found an inverse correlation with $25(\mathrm{OH}) \mathrm{D}$ levels and $\mathrm{BP}^{16}$ In a prospective fashion, the Health Professionals Follow-up Study and The Nurses' Health Study showed that women with $25(\mathrm{OH}) \mathrm{D}$ levels $<15 \mathrm{ng} \mathrm{ml}^{-1}$ had three-fold higher risk of hypertension compared with women with levels $\geqslant 30 \mathrm{ng} \mathrm{ml}^{-1}$. In men, the risk was almost six times higher. ${ }^{33}$

Although the exact pathways bridging hypovitaminosis, vitamin D and hypertension are not completely established, some mechanisms have been suggested. The first and most important mechanism is the regulation of the renin-angiotensin-aldosterone system. Blood pressure is mainly controlled by the renin-angiotensin-aldosterone system, which is known to affect blood vessel tone, extracellular fluid volume and electrolyte homeostasis. Vitamin D acts as a negative endocrine regulator of renin biosynthesis. Vitamin D receptor-knockout mice were found to have a high production of renin and angiotensin II and developed hypertension and cardiac hypertrophy. ${ }^{34}$ The suppression of the renin gene is independent of calcium metabolism. In normal rats, the deficiency of vitamin $\mathrm{D}$ stimulates the expression of renin, whereas the injection of $1,25(\mathrm{OH}) \mathrm{D}_{2}$ reduces the synthesis of renin. ${ }^{34}$ In a cohort study with patients undergoing coronary angiography, the multivariate analysis showed that plasma renin values increased steadily with declining levels of $25(\mathrm{OH}) \mathrm{D} .{ }^{35}$ In the present study, renin was not a predictor of BP.

Notably, the independent relationship between vitamin $\mathrm{D}$ and hypertension is not a homogeneous finding. ${ }^{36,37}$ In the Tromsø study, no difference was found in the risk of hypertension when comparing extreme serum $25(\mathrm{OH}) \mathrm{D}$ levels in subjects who were normotensive. ${ }^{38}$ Some factors related to the study design and, most importantly, to the methods of hypertension diagnosis are among the potential reasons for the divergent findings. ${ }^{39}$ In the majority of previous studies on this topic, BP was assessed by a simple measurement or was selfreported. In the present study, BP was assessed by ABPM, which includes diurnal variations in $\mathrm{BP}$ and better information on the levels of mean arterial pressure during daily life activities. In addition, ABPM correlates best with hypertension-induced target organ damage. ${ }^{40}$ Data focusing on this issue are scarce in nondialyzed CKD population. Apart from our data, only one observational study found an inverse association of 25(OH)D levels with systolic BP by ABPM in nondialyzed patients. ${ }^{27}$

In the current study, we also aimed to investigate the association of $25(\mathrm{OH}) \mathrm{D}$ with CAC. However, contrary to some authors ${ }^{11,12}$ and in agreement with others, ${ }^{14,23}$ we did not find any link between $25(\mathrm{OH}) \mathrm{D}$ and CAC. Calcification is very common in CKD patients and is associated with high mortality in this group. ${ }^{41}$ The pathogenesis of calcification in CKD is not completely understood, but it is certainly multifactorial. It is an active process that involves promoting and inhibiting factors of calcification. The use of some vitamin $\mathrm{D}$ analogs often results in elevated calcium and phosphorus levels, which favors vascular calcification. ${ }^{42}$ On the other side, vitamin D deficiency could lead to calcification. ${ }^{11}$ Some studies have suggested that some of the actions of vitamin D may protect vessels against vascular calcification, such as the downregulation of proinflammatory cytokines and the upregulation of anti-inflammatory cytokines. ${ }^{43}$ In our study, no difference in the prevalence of CAC was observed between the $\mathrm{S}$ - and $\mathrm{M}$-group. Of note, the prevalence of CAC was equally elevated in our patients regardless of the degree of hypovitaminosis D. London et al. ${ }^{14}$ observed that $25(\mathrm{OH}) \mathrm{D}$ was negatively correlated with aorta stiffness, but not with vascular calcification in hemodialysis patients. Interestingly, Barreto et al. ${ }^{44}$ evaluated nondialysis patients and found that low 25(OH)D levels affected mortality independently of vascular calcification. Other negative effects of vitamin $\mathrm{D}$ depletion on the cardiovascular system have also been described, including the development of congestive heart failure and left ventricular hypertrophy. Unfortunately, in our study, those examinations were not performed.

Our study has some limitations, such as the cross-sectional design of the study, which does not provide cause-effect conclusions. In addition, our findings are based on a selected sample of patients with hypovitaminosis D and do not include patients with higher levels of $25(\mathrm{OH}) \mathrm{D}$. However, the impact of severe hypovitaminosis $\mathrm{D}$ on increased BP was observed by demonstrating the impact of the severity of poor vitamin D status on an important cardiovascular risk factor in the earlier stages of CKD.

In conclusion, our study of nondialyzed CKD patients demonstrated that severe hypovitaminosis D is associated with increased systolic BP, which was measured by a gold-standard method. The degree of hypovitaminosis $\mathrm{D}$ was not related to the presence of coronary artery calcification, which was equally elevated in both the severe and mild hypovitaminosis D groups. Studies are necessary to evaluate the benefits of vitamin D supplementation on cardiovascular morbidity and mortality in the earlier stages of CKD. More clarity will come from the ongoing cholecalciferol supplementation study.

\section{CONFLICT OF INTEREST}

The authors declare no conflict of interest. 
1 Holick MF, Chen TC. Vitamin D deficiency: a worldwide problem with health consequences. Am J Clin Nutr 2008; 87: 1080-1086.

2 Artaza JN, Mehrotra R, Norris KC. Vitamin D and the cardiovascular system. Clin J Am Soc Nephrol 2009; 4: 1515-1522.

3 Holick MF. Vitamin D deficiency. N Engl J Med 2007; 357: 266-281.

4 Geleijnse JM. Vitamin D and the prevention of hypertension and cardiovascular diseases: a review of the current evidence. Am J Hypertens 2011; 24: 253-262.

5 Dobnig H, Pilz S, Scharnagl H, Renner W, Seelhorst U, Wellnitz B, Kinkeldei J, Boehm BO, Weihrauch G, Maerz W. Independent association of low serum 25-hydroxyvitamin d and 1,25-dihydroxyvitamin d levels with all cause and cardiovascular mortality. Arch Intern Med 2008; 168: 1340-1349.

6 Martins D, Wolf M, Pan D, Zadshir A, Tareen N, Thadhani R, Felsenfeld A, Levine B, Mehrotra R, Norris K. Prevalence of cardiovascular risk factors and the serum levels of 25-hydroxyvitamin D in the United States: data from the Third National Health and Nutrition Examination Survey. Arch Intern Med 2007; 167: 1159-1165.

7 Drechsler C, Verduijn M, Pilz S, Dekker FW, Krediet RT, Ritz E, Wanner C, Boeschoten EW, Brandenburg VNECOSAD Study Group. Vitamin D status and clinical outcomes in incident dialysis patients: results from the NECOSAD study. Nephrol Dial Transplant 2011; 26: 1024-1032.

8 Wang AY, Lam CW, Sanderson JE, Wang M, Chan IH, Lui SF, Sea MM, Woo J. Serum 25-hydroxyvitamin D status and cardiovascular outcomes in chronic peritoneal dialysis patients: a 3-y prospective cohort study. Am J Clin Nutr 2008; 87: 1631-1638.

9 Ravani P, Malberti F, Tripepi G, Pecchini P, Cutrupi S, Pizzini P, Mallamaci F, Zoccali C. Vitamin D levels and patient outcome in chronic kidney disease. Kidney Int 2009; 75 88-95.

10 Chonchol M, Cigolini M, Targher G. Association between 25-hydroxyvitamin D and cardiovascular disease in type 2 diabetic patients with mild kidney dysfunction. Nephrol Dial Transplant 2008; 23: 269-274.

11 Matias PJ, Ferreira C, Jorge C, Borges M, Aires I, Amaral T, Gil C, Cortez J, Ferreira A. 25-Hydroxyvitamin D3, arterial calcifications and cardiovascular risk markers in haemodialysis patients. Nephrol Dial Transplant 2009; 24: 611-618.

12 García-Canton C, Bosch E, Ramírez A, Gonzalez Y, Auyanet I, Guerra R, Perez MA, Fernández E, Toledo A, Lago M, Checa MD. Vascular calcification and 25-hydroxyvitamin D levels in non-dialysis patients with chronic kidney disease stages 4 and 5 . Nephrol Dial Transplant 2011; 26: 2250-2256.

13 de Boer IH, Kestenbaum B, Shoben AB, Michos ED, Sarnak MJ, Siscovic DS. 25hydroxyvitamin $D$ levels inversely associate with risk for developing coronary artery calcification. J Am Soc Nephrol 2009; 20: 1805-1812.

14 London GM, Guérin AP, Verbeke FH, Pannier B, Boutouyrie P, Marchais SJ, Mëtivier F. Mineral metabolism and arterial functions in end-stage renal disease: potential role of 25-hydroxyvitamin D deficiency. J Am Soc Nephrol 2007; 18: 613-620.

15 Thomas MK, Lloyd-Jones DM, Thadhani RI, Shaw AC, Deraska DJ, Kitch BT, Vamvakas EC, Dick IM, Prince RL, Finkelstein JS. Hypovitaminosis D in medical inpatients. $N$ Engl J Med 1998; 338: 777-783.

16 Scragg R, Sowers M, Bell C. Serum 25-hydroxyvitamin D, ethnicity, and blood pressure in the Third National Health and Nutrition Examination Survey. Am J Hypertens 2007; 20: 713-719.

17 Levin A, Li YA. Vitamin D and its analogues: Do they protect against cardiovascular disease in patients with kidney disease? Kidney Int 2005; 68: 1973-1981.

18 Argilés A, Lorho R, Servel MF, Couret I, Chong G, Mourad G. Blood pressure is correlated with vitamin d(3) serum levels in dialysis patients. Blood Purif 2002; 20 370-375.

$19 \mathrm{KDIGO}$ clinical practice guideline for the diagnosis, evaluation, prevention, and treatment of Chronic Kidney Disease-Mineral and Bone Disorder (CKD-MBD). Kidney Int Supp/ 2009: S1-130.

20 Expert Panel on Detection, Evaluation, and Treatment of High Blood Cholesterol in Adults. Executive Summary of the Third Report of the National Cholestero Education Program (NCEP) Expert Panel on Detection, Evaluation, and Treatment of High Blood Cholesterol in Adults (Adult Treatment Panel III). JAMA 2001; 285: 24862497.

21 Agatston AS, Janowitz WR, Hildner FJ, Zusmer NR, Viamonte Jr M, Detrano R. Quantification of coronary artery calcium using ultrafast computed tomography. J Am Coll Cardiol 1990; 15: 827-832.
22 Cuppari L, Carvalho AB, Draibe SA. Vitamin D status of chronic kidney disease patients living in a sunny country. J Ren Nutr 2008; 18: 408-414.

23 Mehrotra R, Kermah D, Budoff M, Salusky IB, Mao SS, Gao YL, Takasu J, Alder S, Norris K. Hypovitaminosis D in chronic kidney disease. Clin J Am Soc Nephrol 2008, 3: 1144-1151.

24 Gonzalez EA, Sachdeva A, Oliver DA, Martin KJ. Vitamin D insufficiency and deficiency in chronic kidney disease. A single center observational study. Am J Nephrol 2004; 24 503-510.

25 Del Valle E, Negri AL, Aguirre C, Fradinger E, Zanchetta JR. Prevalence of 25(OH) vitamin $\mathrm{D}$ insufficiency and deficiency in chronic kidney disease stage 5 patients on hemodialysis. Hemodial Int 2007; 11: 315-321.

26 Shah N, Bernadini J, Piraino B. Prevalence and correction of $25(\mathrm{OH})$ vitamin D deficiency in peritoneal dialysis patients. Perit Dial Int 2005; 25: 362-366.

27 García-Cantón C, Bosch E, Auyanet I, Ramírez A, Rossique P, Culebras C, Sánchez A, Toledo A, Lago M, Esparza N, Checa MD. 25 hydroxyvitamin D levels and cardiovascular risk in a cohort of patients with advanced chronic kidney disease. Nefrologia 2010; 30: 435-442.

28 Ford ES, Ajani UA, McGuire LC, Lui S. Concentration of serum vitamin D and the metabolic syndrome among U.S. adults. Diab Care 2005; 28: 1228-1230.

29 Lips P. Vitamin D physiology. Prog Biophys Mol Biol 2006; 92: 4-8.

30 Bell NH, Epstein S, Greene A, Shary J, Oexmann MJ, Shaw S. Evidence for alteration of the vitamin D-endocrine system in obese subjects. J Clin Invest 1985; 76: 370-373.

31 Figuiredo-Dias V, Cuppari L, Garcia-Lopes MG, de Carvalho AB, Draibe SA, Kamimura MA. Risk factors for hypovitaminosis $D$ in nondialyzed chronic kidney disease patients. J Ren Nutr 2012; 22: 4-11.

32 Muray S, Parisi E, Cardús A, Craver L, Fernández E. Influence of vitamin D receptor gene polymorphisms and 25-hydroxyvitamin $\mathrm{D}$ on blood pressure in apparently healthy subjects. J Hypertens 2003; 21: 2069-2075.

33 Forman JP, Giovannucci E, Holmes MD, Bischoff-Ferrari HA, Tworoger SS, Willet WC Curhan GC. Plasma 25-hydroxyvitamin D levels and risk of incident hypertension. Hypertension 2007; 49: 1063-1069.

$34 \mathrm{Li} \mathrm{YC,} \mathrm{Kong} \mathrm{J,} \mathrm{Wei} \mathrm{M,} \mathrm{Chen} \mathrm{ZF,} \mathrm{Liu} \mathrm{SQ,} \mathrm{Cao} \mathrm{LP.} \mathrm{1,25-Dihydroxyvitamin} \mathrm{D(3)} \mathrm{is} \mathrm{a}$ negative endocrine regulator of the renin-angiotensin system. J Clin Invest 2002; 110: 229-238.

35 Tomaschitz A, Pilz S, Ritz E, Grammer T, Drechsler C, Boehm BO, März W. Independent association between 1,25-dihydroxyvitamin D, 25-hydroxyvitamin D and the renin-angiotensin system: the Ludwigshafen Risk and Cardiovascular Health (LURIC) study. Clin Chim Acta 2010; 411: 1354-1360.

36 Snijder MB, Lips P, Seidell JC, Visser M, Deeg DJ, Dekker JM, van Dam RM. Vitamin D status and parathyroid hormone levels in relation to blood pressure: a population-based study in older men and women. J Intern Med 2007; 261: 558-565.

37 Scragg R, Holdaway I, Singh V, Metcalf P, Baker J, Dryson E. Serum 25-hydroxycholecalciferol concentration in newly detected hypertension. Am J Hyperten 1995; 8 429-432.

38 Jorde R, Figenschau Y, Emaus N, Hutchinson M, Grimnes G. Serum 25-hydroxyvitamin D levels are strongly related to systolic blood pressure but do not predict future hypertension. Hypertension 2010; 55: 792-798.

39 Ullah MI, Uwaifo GI, Nicholas WC, Koch CA. Does vitamin d deficiency cause hypertension? Current evidence from clinical studies and potential mechanisms. Int J Endocrinol 2010; 2010: 579640.

40 Verdecchia P. Prognostic value of ambulatory blood pressure: current evidence and clinical implications. Hypertension 2000; 35: 844-851.

41 Watanabe R, Lemos MM, Manfredi SR, Draibe SA, Canziani ME. Impact of cardiovascular calcification in nondialyzed patients after 24 months of follow-up. Clin J Am Soc Nephrol 2010; 5: 189-194.

42 Teng M, Wolf M, Lowrie E, Ofsthun N, Lazarus JM, Thadhani R. Survival of patients undergoing hemodialysis with paracalcitol or calcitriol therapy. N Engl Med 2003 349: 446-456.

43 Guessous I, Bochud M, Bonny O, Burnier M. Calcium, vitamin D and cardiovascular disease. Kidney Blood Press Res 2011; 34: 404-417.

44 Barreto DV, Barreto FC, Liabeuf S, Temmar M, Boitte F, Choukroun G, Fournier A, Massy ZA. Vitamin D affects survival independently of vascular calcification in chronic kidney disease. Clin J Am Soc Nephrol 2009; 4: 1128-1135. 